$1-10-2008$

\title{
Mechanical Properties of a Reinforced Composite Polymer Electrolyte Membrane and its Simulated Performance in PEM Fuel Cells
}

Yaliang Tang

University of Delaware

Ahmet Kusoglu

University of Delaware

Anette M. Karlsson

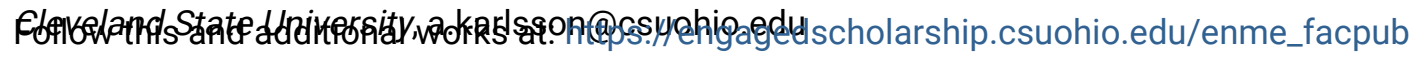

JPlareloffthealltarteanical Engineering Commons

Hobikekfitesofeelasware this work benefit you? Let us know!

Bithblishegrisirstatement

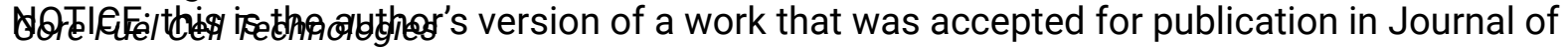
Power Sources. Changes resulting from the publishing process, such as peer review, editing, corrections, structural formatting, and other quality control mechanisms may not be reflected in

this document. Changes may have been made to this work since it was submitted for publication. A definitive version was subsequently published in Journal of Power Sources, 175, 2, (01-10-2008); 10.1016/j.jpowsour.2007.09.093

\section{Original Citation}

Tang, Y., Kusoglu, A., Karlsson, A. M., 2008, "Mechanical Properties of a Reinforced Composite Polymer Electrolyte Membrane and its Simulated Performance in PEM Fuel Cells," Journal of Power Sources, 175(2,) pp. 817-825.

This Article is brought to you for free and open access by the Mechanical Engineering Department at EngagedScholarship@CSU. It has been accepted for inclusion in Mechanical Engineering Faculty Publications by an authorized administrator of EngagedScholarship@CSU. For more information, please contact library.es@csuohio.edu. 


\section{Authors}

Yaliang Tang, Ahmet Kusoglu, Anette M. Karlsson, Michael H. Santare, Simon Cleghorn, and William B. Johnson

This article is available at EngagedScholarship@CSU: https://engagedscholarship.csuohio.edu/enme_facpub/30 


\title{
Mechanical properties of a reinforced composite polymer electrolyte membrane and its simulated performance in PEM fuel cells
}

\author{
Yaliang Tang ${ }^{\mathrm{a}}$, Ahmet Kusoglu ${ }^{\mathrm{a}}$, Anette M. Karlsson ${ }^{\mathrm{a}, *}$, Michael H. Santare ${ }^{\mathrm{a}}$, \\ Simon Cleghorn ${ }^{\mathrm{b}}$, William B. Johnson ${ }^{\mathrm{b}}$ \\ a Department of Mechanical Engineering, University of Delaware, DE 19716, United States \\ ${ }^{\mathrm{b}}$ Gore Fuel Cell Technologies, 201 Airport Road, P.O. Box 1488, Elkton, MD 21922-1488, United States
}

\section{Introduction}

Proton exchange membrane fuel cells (PEMFCs) have emerged as an alternative power source for transportation, primarily due to their high-energy efficiency and clean operation. Typical PEMFCs operate at temperatures ranging from ambient to about $100^{\circ} \mathrm{C}$ and at a range of relative humidities. Perfluorosulfonic acid (PFSA) materials, such as NAFION ${ }^{\circledR}$ membranes, ${ }^{1}$ are used as the electrolyte in these fuel cells due to their thermal, mechanical and chemical stability in addition to their high proton conductivity. However, PFSA membranes are subjected to cyclical hygro-thermal stresses during operation which can significantly reduce their useful life expectancy [1-3]. For example, mechanical failures in membrane electrode assemblies (MEAs) have been precipitated solely by cycling between wet and dry

\footnotetext{
* Corresponding author. Tel.: +1 302831 6437; fax: +1 3028313619. E-mail address: karlsson@udel.edu (A.M. Karlsson).

I NAFION is a registered trademark of E.I. DuPont De Nemours \& Co.
}

operating conditions without electric potential or reactive gases [4-6]. Theoretical studies [7-10] have shown how the mechanical stresses induced due to the hygro-thermal loading may play an important role in these failures.

In order to develop thin, high-strength electrolyte membranes that can withstand more severe operating conditions and offer smaller proton resistance, reinforced composite membranes have been proposed, e.g., $[11,12]$. The reinforcement can increase the mechanical strength, and may allow for thinner membranes and the use of lower equivalent weight ionomers, resulting in lower resistance to proton conductivity. Several attempts have been made to develop composite membranes. For example, porous polytetrafluoroethylene has been impregnated with PFSA solution, in order to make thin, cation transporting membranes [12]. Alternatively, woven polytetrafluoroethylene (PTFE)-reinforced membranes were developed by DuPont, referred to as NAFION ${ }^{\circledR} 324$ and 417 membranes [11]. Although the woven PTFE-reinforced membranes are mechanically strong, they are relatively thick, and therefore have high proton resistance making them less attractive for 
PEMFCs applications. Kolde et al. [13] reported longer lifetimes for fuel cells with reinforced membranes than those with homogeneous PFSA membranes, and suggested that the in-plane dimensional stability of the membrane was a significant factor in the improved durability. By forming a thin, air-impermeable membrane of PFSA, reinforced with a microporous, expanded polytetrafluoroethylene (ePTFE) [14,15], W.L. Gore \& Associates has developed a new micro-reinforced polymer electrolyte, the GORE-SELECT ${ }^{\circledR}$ ionomer composite membrane. ${ }^{2}$ Tests of GORE-SELECT ${ }^{\circledR}$ membranes have shown improved tear strength, greater dimensional stability, high membrane proton conductance and improved water distribution in operating fuel cells $[3,16-18]$. In studies where different membranes have been compared in similar fuel cell operation conditions, GORE-SELECT ${ }^{\circledR}$ membrane is by far the most durable membrane $[19,20]$.

In this paper, we investigate the mechanical properties of an experimental GORE-SELECT ${ }^{\circledR}$ membrane that uses ePTFE reinforcement. For convenience, we refer to this microreinforced PFSA polymer electrolyte as Membrane A in the following sections. Based on our previous work, we have found that Young's modulus, the proportional limit stress and the swelling due to water uptake are important parameters that influence the mechanical response of the electrolyte membrane during fuel cell operation [7-9]. In addition, these previous studies indicated that the mechanical properties are strongly dependent on the environmental conditions. Therefore, we investigate the influence of temperature and relative humidity on these mechanical properties of Membrane A, by means of tensile testing in a custom-built, environmentally controlled chamber. We also measure the break stress and break strain to complete the comparison of results with our previous experimental work. Throughout the paper, "swelling" refer to the geometric change due to water absorption and "expansion" refer to the geometric change due to a temperature change.

Finite element simulations are used to explore the consequences of the measured properties of Membrane $\mathrm{A}$ on the evolution of stress and strain in a PEMFC assembly. The finite element model used is a two-dimensional (2D) unit cell, representative of a repeating section of a PEMFC assembly with hygro-thermal loading. The operating conditions for the numerical model are determined from fuel cell accelerated testing procedures [11,21].

In what follows, we will first discuss the experimental setup and results, and then discuss the mechanics-based numerical simulations that utilize the experimental data to explore the stress and strain evolution in an operating fuel cell.

\section{Experimental investigations}

\subsection{Experiment setup}

In the experimental investigation, a composite membrane, "Membrane A," is evaluated for selected mechanical properties

${ }^{2}$ GORE-SELECT is a trademark of W.L. Gore \& Associates Inc. as a function of temperature and relative humidity by means of tensile testing in an environmental control chamber.

Membrane A was produced by W.L. Gore \& Associates in sheets with a nominal thickness of $20 \mu \mathrm{m}$. The production method gives two distinct in-plane directions: "machine" and "transverse" directions. To investigate if the hygro-thermalmechanical properties differ for these two directions, tensile test specimens were made in both the machine and transverse directions by cutting the membrane sheet into rectangular pieces $100 \mathrm{~mm}$ in length and $10 \mathrm{~mm}$ in width.

Tensile tests were conducted using an MTS Alliance ${ }^{\mathrm{TM}} \mathrm{RT} / 5$ material testing system fitted with an ESPEC custom-designed environmental chamber. The test setup is shown in Fig. 1. To compare results with the properties of the unreinforced PFSA membrane previously tested (NAFION ${ }^{\circledR} 112$ membrane), we used the experimental procedures we developed previously [1], summarized in the following. Tests were conducted at 16 temperature and humidity combinations, i.e., at four temperatures $\left(25,45,65\right.$ and $\left.85^{\circ} \mathrm{C}\right)$ and four relative humidities $(30,50,70$ and 90\%) [1]. Five specimens were tested at each temperature and humidity combination. For each specimen, the thickness and width were measured with a micrometer and a caliper, respectively, at three locations along the sample before testing. The averages of these three measurements were used as the nominal dimensions of the sample. Each specimen was then aligned with the machine axis and clamped in a pair of vise-action grips. The gauge length was adjusted to $50 \mathrm{~mm}$ as determined by the grip separation (Fig. 1). To achieve the proper environmental conditions in the chamber, the temperature was increased to the desired temperature and allowed to stabilize. After the temperature was stabilized, the crosshead was manually adjusted until

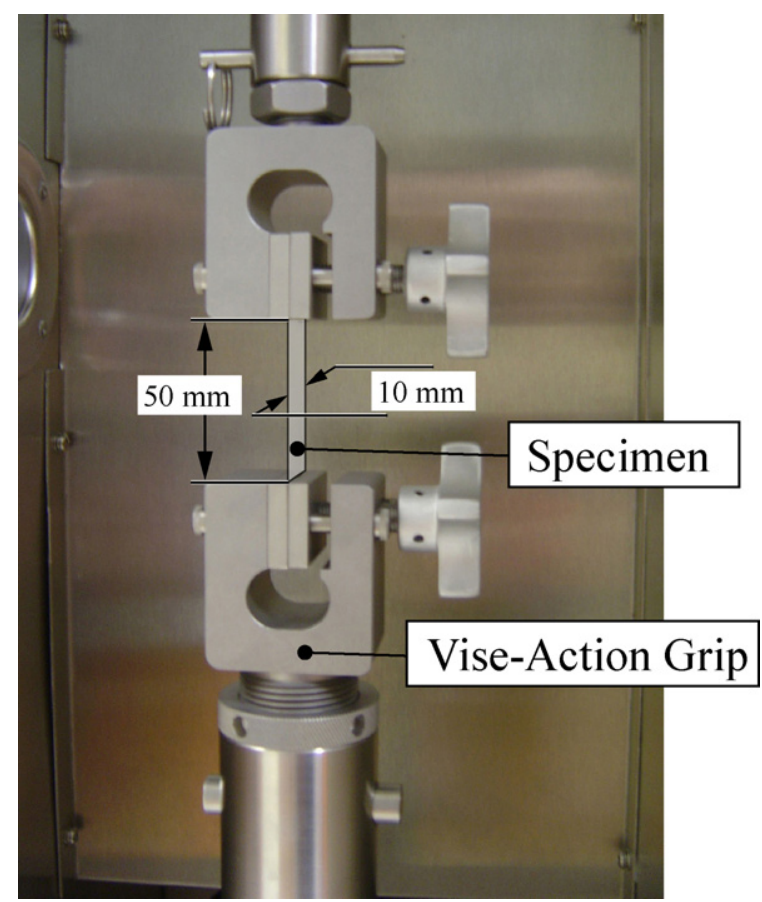

Fig. 1. Membrane tensile test setup. The specimen with nominal gauge length of $50 \mathrm{~mm}$ and width of $10 \mathrm{~mm}$ is aligned with the extension rod by a pair of vise-action grips. 
the compressive stress developed in the specimen due to the thermal expansion was brought back to zero. Then, the relative humidity (RH) was increased in increments of $10 \%$ to reach the desired RH. After each incremental increase, the crosshead was again manually adjusted to compensate for the swelling. Since the temperature was kept constant during the process, the changes in the specimen length were only due to the swelling of the membrane. Therefore, the recorded value of the crosshead change was taken as a measure of the dimensional change of the membrane due to a change in relative humidity at a fixed temperature. The final gauge length of the specimen is the original length plus the total displacements of the crosshead due to the changes in environmental conditions (from ambient to test point). This length is used as the reference length when determining the strain of the membrane due to mechanical loading. In a separate calibration procedure, an extensometer was used to confirm that the crosshead displacement matched the actual elongation of the PSFA specimens.

The stress-strain relationship was calculated from the forcedisplacement data recorded during the tensile testing. From this relationship, we determined Young's modulus, the proportional limit stress, the break stress and the break strain for each specimen at the specified temperature-humidity combination.

\subsection{Experimental results}

\subsubsection{Stress-strain response}

Figs. 2 and 3 show typical engineering stress-strain behavior for Membrane A along the machine direction. Fig. 2 shows the stress-strain curves for several temperatures at $50 \%$ relative humidity. The curves shift monotonically "downward" with increasing temperature, corresponding to decreasing tensile stiffness and strength as the temperature increases. The elongation at break increases with increasing temperature. Sim-

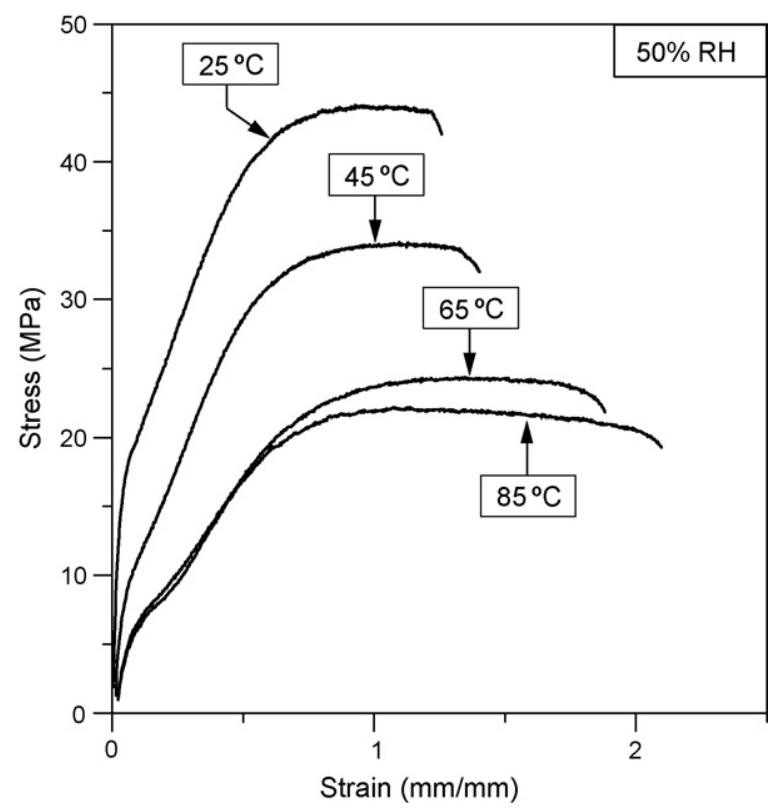

Fig. 2. Engineering stress as a function of engineering strain for tensile tests of Membrane A at $25,45,65$ and $85^{\circ} \mathrm{C}$ at $50 \%$ relative humidity (machine direction).

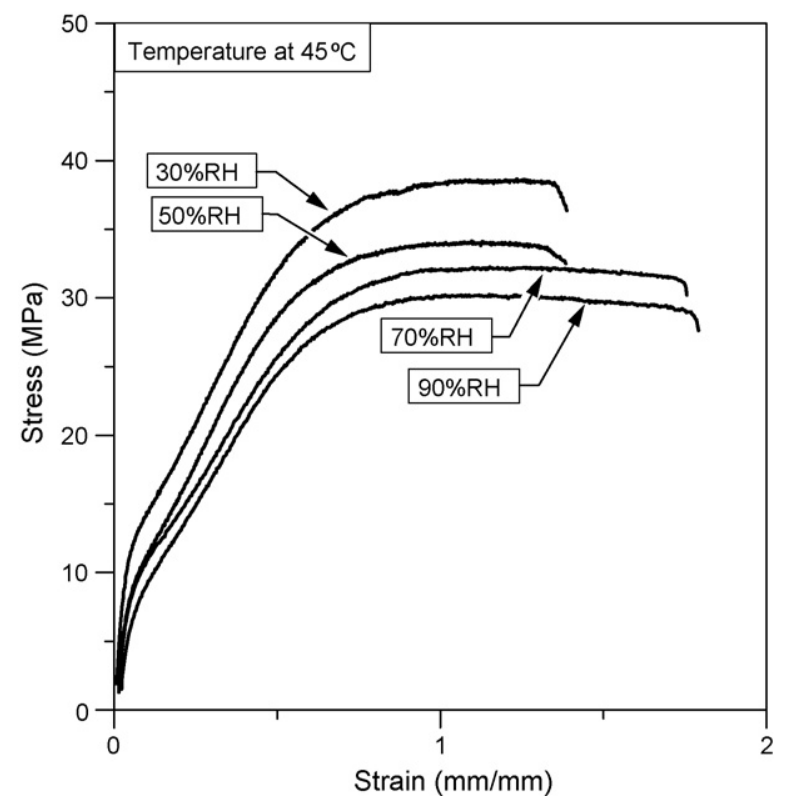

Fig. 3. Engineering stress as a function of engineering strain for tensile tests of Membrane A at 30, 50, 70 and $90 \%$ relative humidity at $45^{\circ} \mathrm{C}$ (machine direction).

ilarly, the stress-strain curves shift downward with increasing humidity (Fig. 3). Moreover, the experimental results indicate that Membrane A is anisotropic (Fig. 4) with higher stiffness and strength in the transverse direction, especially in the strain hardening region. Interestingly, our previous experimental data on unreinforced extruded PFSA membranes showed that those membranes have higher strength in the machine direction [8].

Based on monotonic engineering stress-strain curves from tensile tests (Figs. 2 and 3), it is not possible to identify the onset of yielding. Instead, we define a "proportional limit stress" as the intersection of the tangents to the initial linear response and a linearization of the initial strain hardening response (Fig. 5). The slope of the initial linear response is taken as Young's modulus.

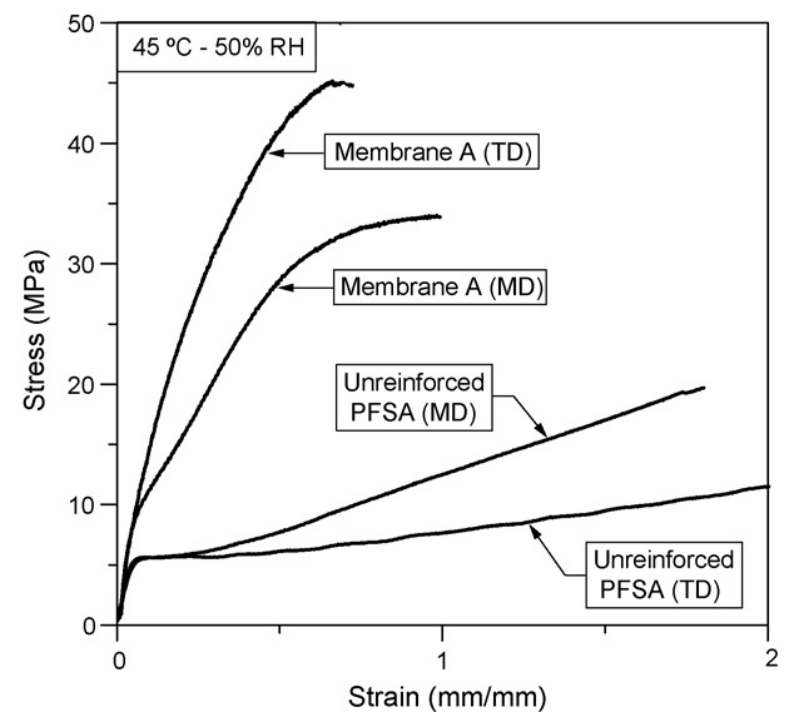

Fig. 4. Engineering stress as a function of engineering strain for tensile tests of Membrane $\mathrm{A}$ and an unreinforced membrane [8] at $45^{\circ} \mathrm{C}$ and 50\% RH. TD: transverse direction, MD: machine direction. 


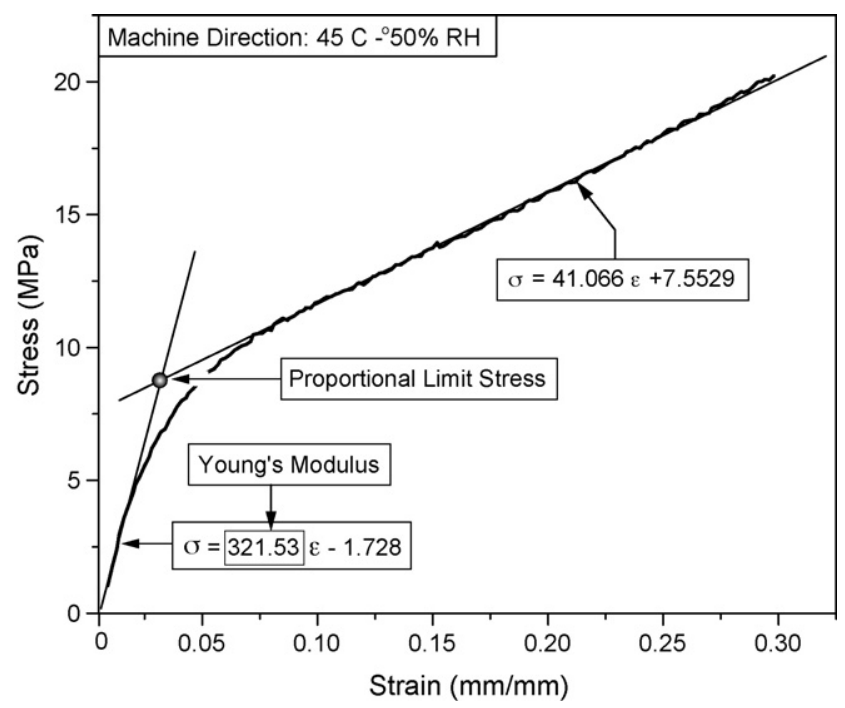

Fig. 5. Definition of proportional limit stress and Young's modulus. Young's modulus is defined as the slope of the initial linear part of stress-strain curve. "Proportional limit stress" is defined as the intersection of the tangents to the initial linear response and a linearization of the initial strain hardening response. $\varepsilon$ is engineering strain.

\subsubsection{Characteristic mechanical properties}

Young's modulus, proportional limit stress, break stress, and break strain are determined from each engineering stress-strain curve and the average value for each temperature-humidity com-

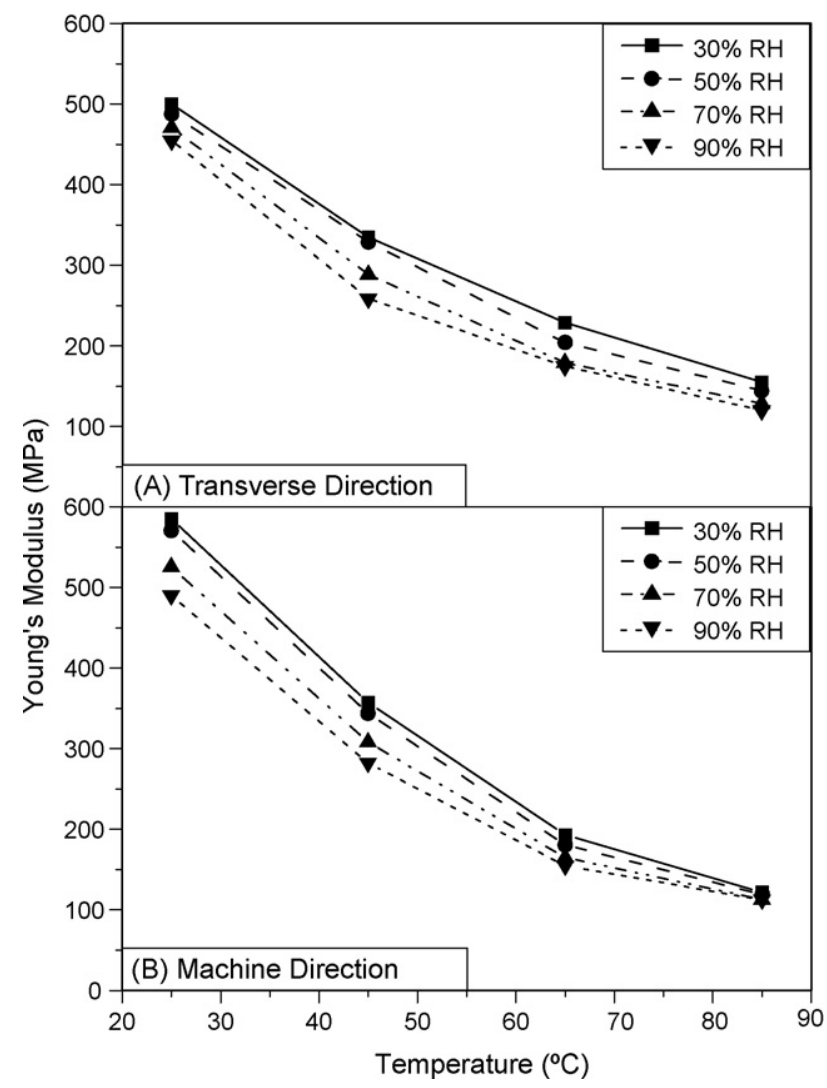

Fig. 6. Young's modulus of Membrane A as a function of temperature at various relative humidities: (A) transverse direction and (B) machine direction. (The markers are the measured data (average of five specimens) and the lines are "guide for the eye."). bination is plotted in Figs. 6-9. The variation in the experimental data is relatively low: the standard deviations for both Young's modulus and the proportional limit stress are less than 5\%, whereas the standard deviations of break stress and break strain are usually less than $15 \%$.

The results indicate that Young's modulus decreases with increasing temperature and relative humidity (Fig. 6). In a similar manner, the proportional limit stress and the break stress decrease as the temperature and relative humidity increase (Figs. 7 and 8, respectively). However, relative humidity has little or no effect on the break strain (Fig. 9), but higher temperatures appear to result in higher break strains. The overall response of Membrane A is similar to what was observed in unreinforced PFSA membranes [1]. However, Young's modulus and the proportional limit stress are in general higher for Membrane A than the unreinforced PFSA membrane.

As seen from Figs. 6-9, the changes in mechanical properties as a function of temperature and relative humidity are similar in the transverse direction and the machine direction. However, for a given temperature-humidity state, Young's modulus, proportional limit stress and break stress in the transverse direction are slightly higher than those in the machine direction are. The break strain in the transverse direction, however, is smaller than that in the machine direction.

\subsubsection{Swelling}

PFSA-type material is hydrophilic in nature, therefore the membranes will swell in response to an increase in humid-

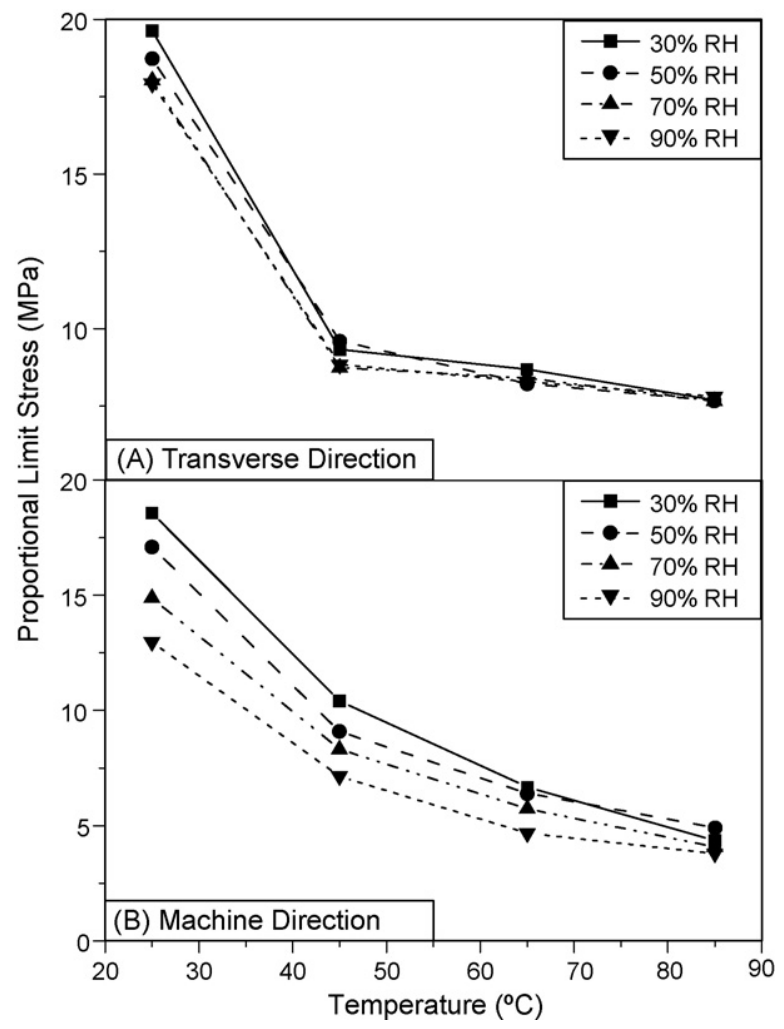

Fig. 7. Proportional limit stress of Membrane $A$ as a function of temperature at various relative humidities: (A) transverse direction and (B) machine direction. (The markers are the measured data (average of five specimens) and the lines are "guide for the eye."). 


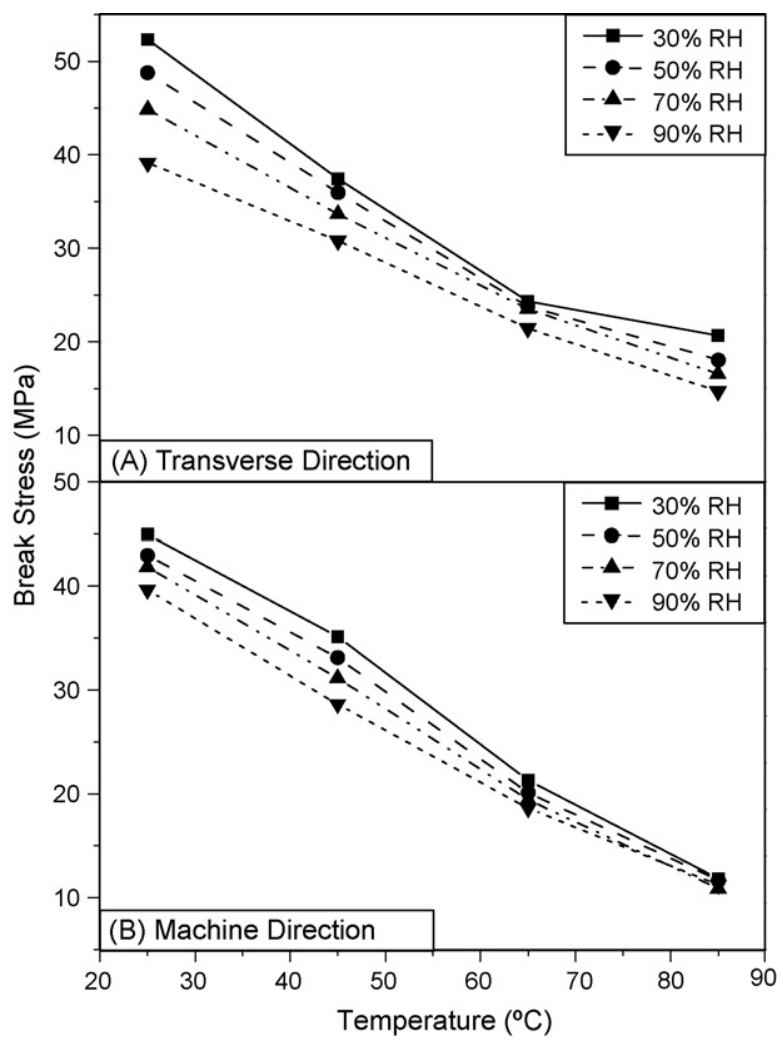

Fig. 8. Break stress of Membrane A as a function of temperature at various relative humidities: (A) transverse direction and (B) machine direction. (The markers are the measured data (average of five specimens) and the lines are "guide for the eye.").

ity. In our previous numerical simulations, we have shown that swelling is the predominant driving force in the development of mechanical stresses in the PEM during fuel cell operation [7-9]. Therefore, it is important to characterize the swelling of the membrane as a function of temperature and relative humidity. Consequently, in-plane dimensional changes as a function of relative humidity at $25,45,65$, and $85^{\circ} \mathrm{C}$ in both the transverse and machine directions were measured and are summarized in Fig. 10. The values presented are the average values of the five measured specimens and in each case, the standard deviation is less than $10 \%$ of the average.

We define the swelling coefficient, $\beta$, as [8]

$\beta=\frac{\partial\left(\Delta l / l_{0}\right)}{\partial(R H)}$

where $l_{0}$ is the original length, $\Delta l$ is the change of length and $R H$ is the relative humidity. Thus, the swelling coefficient is the (local) slope of the curves in Fig. 10.

We see from Fig. 10, that the dimensional change increase is almost proportional to the increase in relative humidity for all temperatures investigated. Thus, the swelling coefficient is nearly constant, with only a minor dependence on temperature. The maximum dimensional change is very low, only about $2 \%$. As a point of comparison, the dimensional change for Membrane A is only about $20 \%$ of that measured in the unreinforced PFSA membrane [1]. Moreover, the swelling coefficient for the unreinforced PFSA membrane increases with increasing temperature,

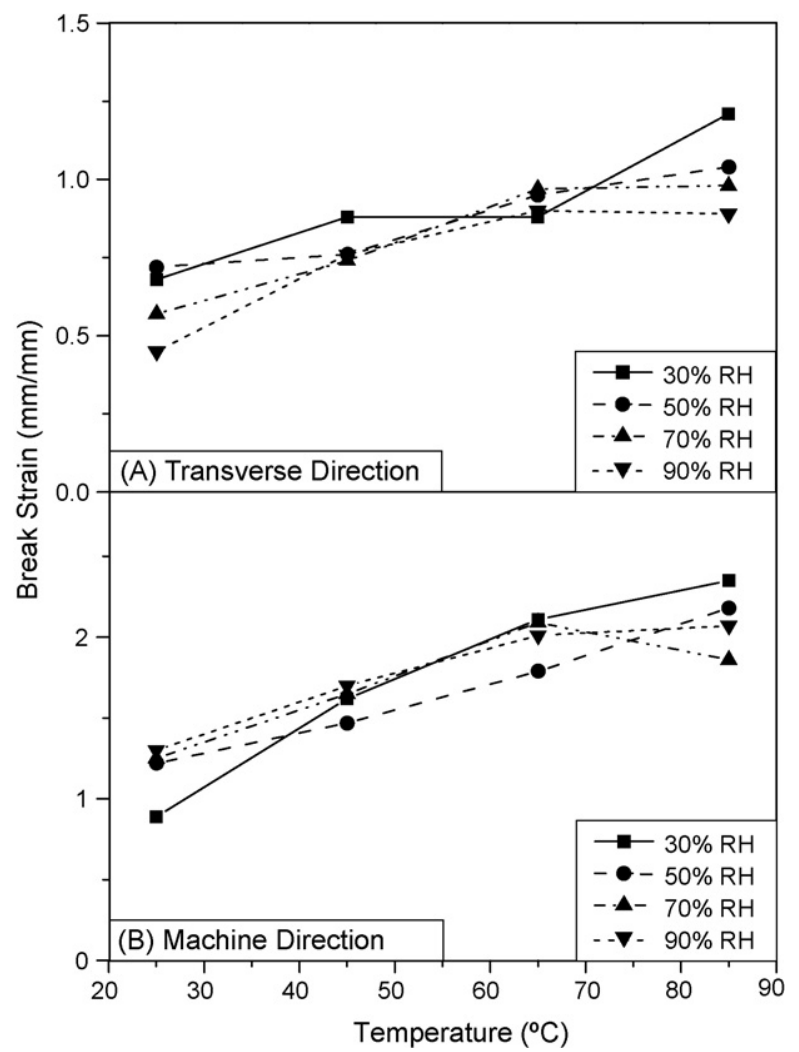

Fig. 9. Break strain of Membrane A as a function of temperature at various relative humidities: (A) transverse direction and (B) machine direction. (The markers are the measured data (average of five specimens) and the lines are "guide for the eye.").

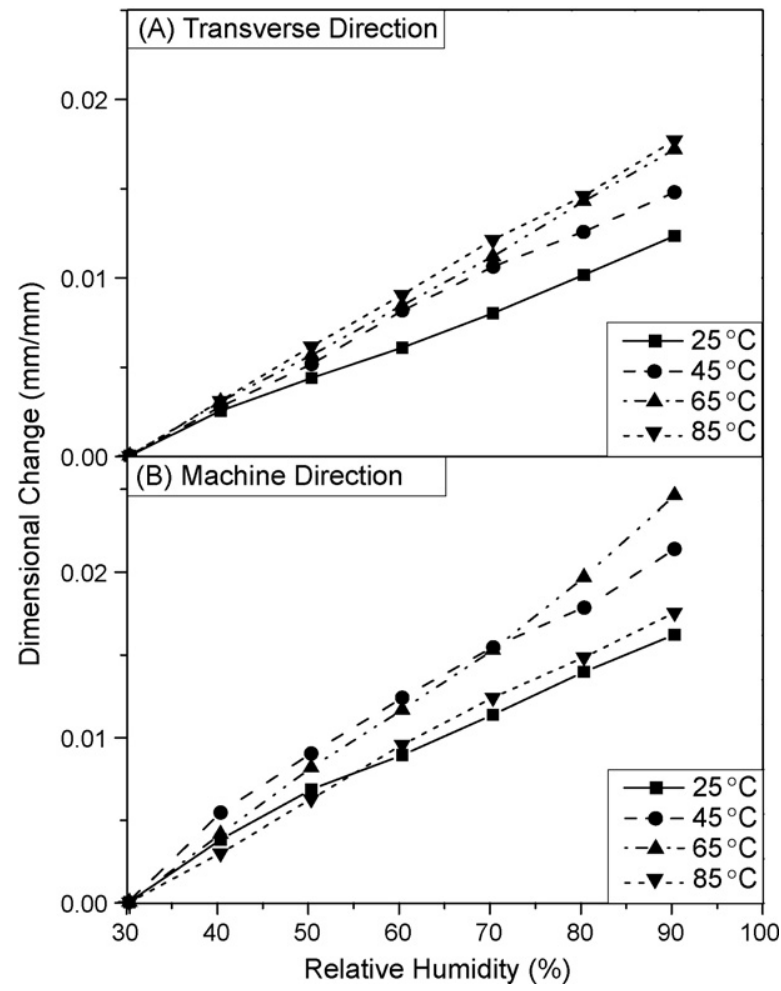

Fig. 10. Dimensional changes of Membrane A as a function of relative humidity at various temperatures: (A) transverse direction and (B) machine direction. (The markers are the measured data (average of five specimens) and the lines are "guide for the eye."). 
whereas the swelling coefficient of Membrane A is nearly temperature independent. One final difference is that Membrane A exhibits a slightly larger percentage dimensional change in the machine direction than in the transverse direction, resulting in mildly anisotropic swelling. The in-plane swelling in the unreinforced PFSA membranes is nearly isotropic [1].

\section{Simulation of fuel cell duty cycles}

\subsection{Numerical model}

To investigate how Membrane A responds mechanically in a PEMFC, the measured properties presented above are incorporated into a numerical simulation of a simplified fuel cell operation. In particular, the evolution of hygro-thermally induced mechanical stresses is investigated via the commercial finite element program ABAQUS [22] and the results are compared with those of unreinforced PFSA membranes. The loading scheme is based on the approach of "accelerated humidity cycling tests," which is a procedure used to simulate automotive fuel cell duty cycles and to isolate failure mechanisms associated with mechanical failure, e.g., [21].

For these simulations, we adapted a unit cell model from our previous studies [9], where the mechanical response of unreinforced PFSA membrane was investigated. The numerical simulation models a typical segment of the fuel cell assembly as a two-dimensional unit cell, consisting of bipolar plates, gas diffusion electrodes (GDE) and polymer electrolyte membrane with continuous mechanical boundary conditions (Fig. 11). Throughout the analysis, a fixed displacement is applied at the top edge of the cell, corresponding to rigid clamping applied during the fuel cell stack assembly.

Cyclic humidity loading is simulated, by first applying an initial hygro-thermal increase to reach the maximum operating temperature and humidity $\left(85^{\circ} \mathrm{C}-95 \% \mathrm{RH}\right)$, followed by cycling the relative humidity, with a linear rate of change,

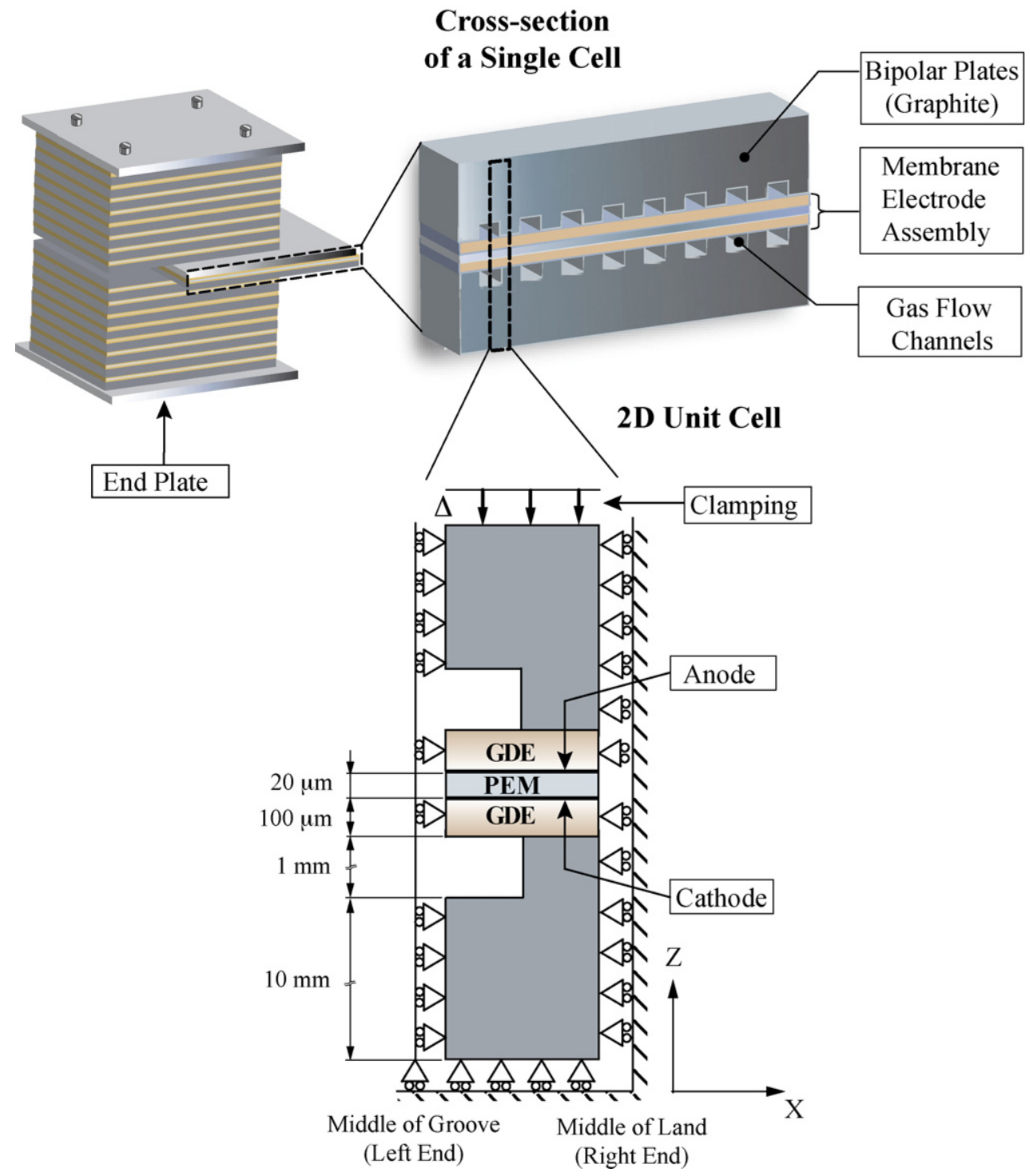

Fig. 11. The geometry of the unit cell used in the numerical analysis is shown with the mechanical boundary conditions. A fixed displacement is applied at the top edge of the cell corresponding to the clamping of a single cell between end plates. 


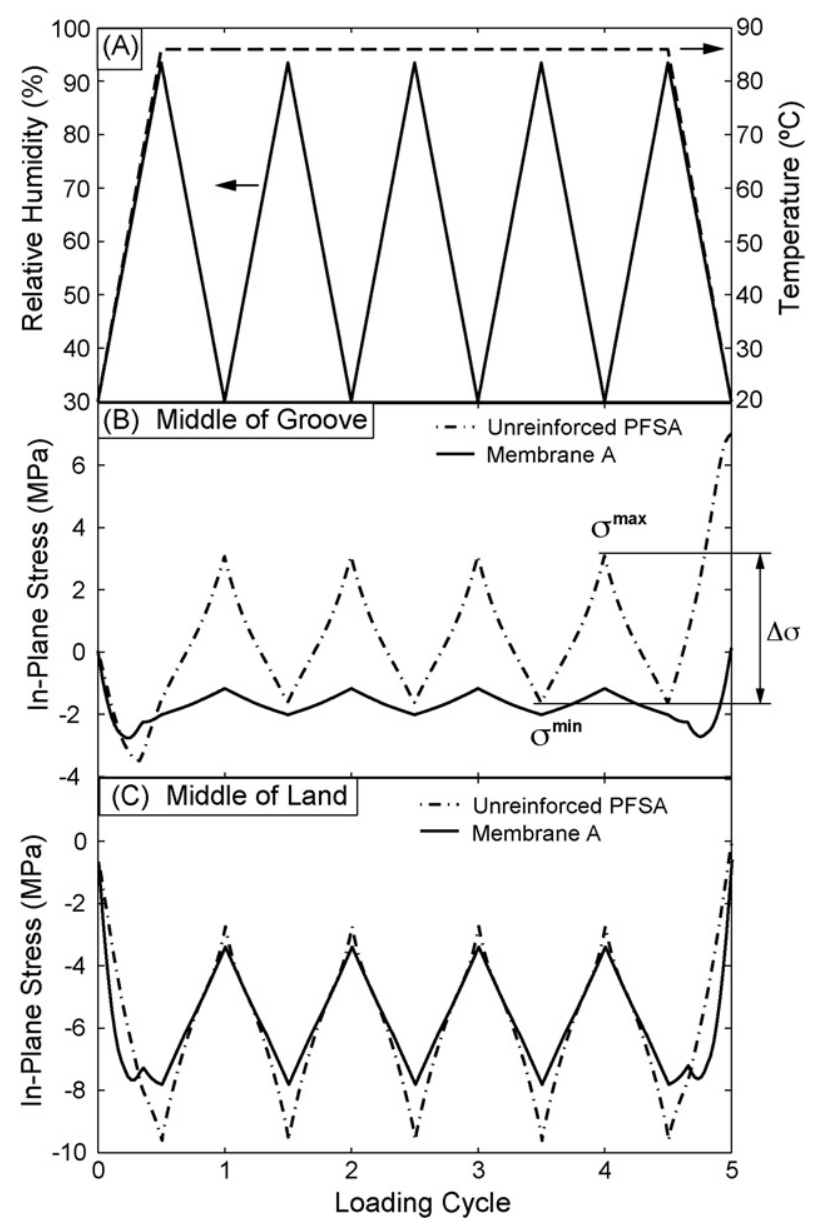

Fig. 12. (A) The hygro-thermal loading scheme used in the analysis to simulate the accelerated automotive fuel cell duty cycle and evolution of in-plane stresses during cyclic (B) at the left, and (C) the right end of the cathode side of PEM for unreinforced PFSA membrane $(20 \mu \mathrm{m})$ and Membrane A $(20 \mu \mathrm{m})$.

between the initial (30\% RH) and the hydrated state (95\% RH) four times at the cathode side of PEM (Fig. 12A). The anode side is kept at the initial relative humidity (30\% $\mathrm{RH})$ throughout the cycling imposing a linear humidity gradient from the cathode to anode during the cycling. Based on this simulation scheme, the influence of the membrane's properties on the cyclic stresses and plastic deformation is investigated. Further details of the finite element model, geometry, material properties and the mechanical model characterizing the elasto-plastic behavior of an unreinforced PFSA membrane, can be found in Kusoglu et al. [9].

The dimensions of the unit cell used in the simulations are shown in Fig. 11, where the thickness of Membrane A $(20 \mu \mathrm{m})$ is incorporated. The properties for the unreinforced PFSA membrane were based on a membrane with a thickness of $50 \mu \mathrm{m}$. Consequently, we here consider unreinforced membranes of both 20 and $50 \mu \mathrm{m}$ thickness. The length of the unit cell is $1 \mathrm{~mm}$. The swelling strains, Young's modulus and the yield strength (which is assumed equal to the proportional limit stress) are defined as functions of temperature and relative humidity, based on the experimental data presented above for Membrane A. As noted above, Membrane A is anisotropic in the plane. How- ever, for simplicity the in-plane properties corresponding to the machine direction are implemented, since this direction exhibits a lower yield strength and higher swelling strain, resulting in the most severe load case.

We were only able to measure the in-plane swelling strains for Membrane A with the current experimental apparatus. Thus, we make the following estimate for the swelling strain in the thickness direction. First, we assume that the swelling of the unreinforced membrane is isotropic. This results in a total volumetric strain of approximately $40 \%$ from the beginning to the end of a hygro-thermal cycle. Next, we assume that Membrane A has the same volumetric water uptake as the unreinforced PFSA membrane [9]. Based on these assumptions and the measured in-plane data for Membrane A, we can calculate a reasonable swelling coefficient in the thickness direction. This is a conservative assumption, giving an upper bound of volume change and therefore, an upper limit of the resulting stress. The evolution of the swelling strains in the in-plane and the thickness directions during the first hygro-thermal cycle are depicted in Fig. 13 for both the unreinforced PFSA membrane and Membrane A. Based on these calculations, Membrane A exhibits anisotropic swelling and swells more in the thickness direction than the unreinforced membrane, while in the in-plane directions the swelling strain is reduced $90 \%$ as compared to that of the unreinforced PFSA membranes.

\subsection{Results from the numerical simulations}

Previous studies have shown that the in-plane stress is the dominant stress component during hygro-thermal loading [7-9]. Thus, for simplicity, we will focus the following discussion on the in-plane stresses, Fig. 12B and C. Furthermore, since the onset of plasticity along with cyclic plasticity, is related to fatigue, e.g., [23], the plastic strain is monitored and shown in Fig. 14. Due to the humidity gradient, the largest stresses and strains occur at the cathode side of the membrane [9], thus only these values are shown in the figures.

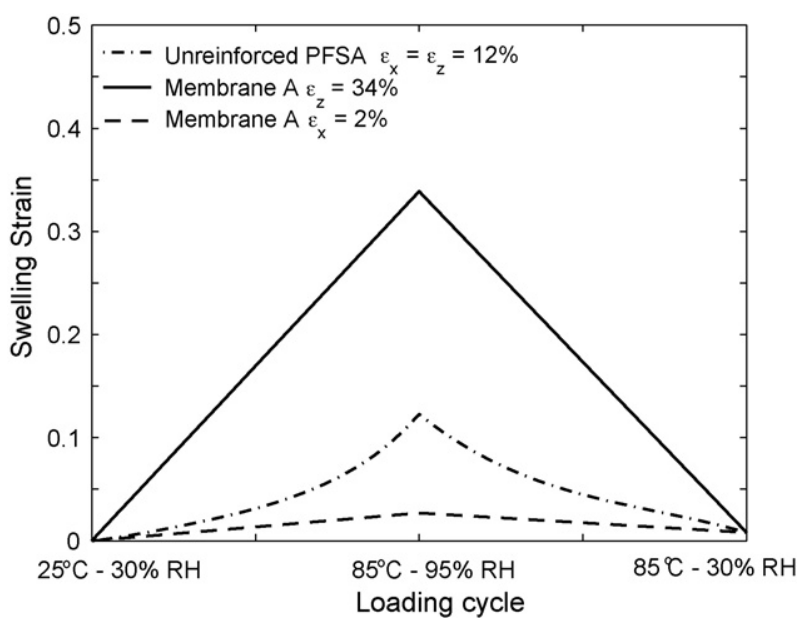

Fig. 13. Swelling strains during one hygro-thermal fuel cell duty cycle for unreinforced PFSA membrane and Membrane A. The swelling behavior of the unreinforced PFSA is assumed isotropic. $\varepsilon$ is the strain. 
We will first investigate both reinforced and unreinforced membranes with the same thickness $(20 \mu \mathrm{m})$ to focus on the importance of the material properties. In general, the magnitudes of the maximum and minimum stresses, $\sigma^{\max }$ and $\sigma^{\min }$, reached during the cyclic loading are lower for Membrane A than those of the unreinforced PFSA membrane (Fig. 12). This is due to the higher in-plane swelling of the unreinforced membrane as compared to that of Membrane A. In addition, the stress amplitude, $\Delta \sigma=\sigma^{\mathrm{max}}-\sigma^{\mathrm{min}}$ is lower for Membrane A than the unreinforced PFSA membrane (Fig. 12).

In the middle of the groove (left side of the unit cell in Fig. 11), the magnitudes of the in-plane stresses and the stress amplitudes are significantly higher for the unreinforced PFSA membrane than for Membrane A as shown in Fig. 12B. This is due to the higher in-plane swelling in the unreinforced PFSA membrane compared to Membrane A. In the middle of the land (right side of the unit cell in Fig. 11), the geometric constraints result in compressive in-plane stresses for both membranes as shown in Fig. 12C. Moreover, the constraints prevent the membranes from expanding out-of-plane, leading to a state of stress dominated by hydrostatic compression (not shown for simplicity). The yield criterion used in our simulation, von Mises yield criterion [24], is a function of the deviatoric stress components only, and assumes that the hydrostatic component does not contribute to yielding, where the deviatoric stress, $S_{i j}$, is given by

$S_{i j}=\sigma_{i j}-\bar{\sigma} \delta_{i j}$

where $\bar{\sigma}=\frac{1}{3}\left(\sigma_{11}+\sigma_{22}+\sigma_{33}\right)$ is the hydrostatic pressure, and $\delta_{i j}$ is Kronecker's delta, defined by

$\delta_{i j}= \begin{cases}1 ; & i=j \\ 0 ; & i \neq j\end{cases}$

Therefore, the constraints in the middle of the land suppress the plastic yielding according to the Mises yield criterion. However, this effect is only noticeable for the unreinforced PFSA membrane, since Membrane A remains elastic throughout the cycle due to its low in-plane swelling and higher

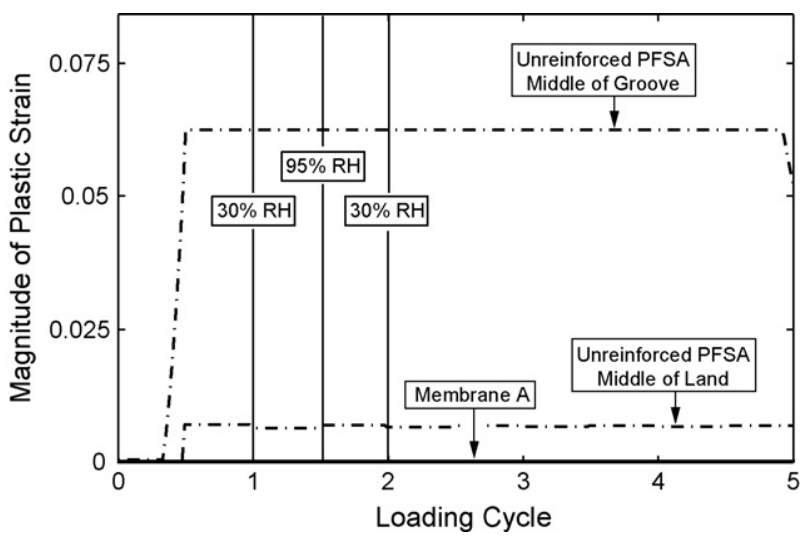

Fig. 14. The developing plastic strain magnitude at the middle of the groove and the middle of the land of the cathode side of the PEM for the unreinforced PFSA membrane and Membrane A.

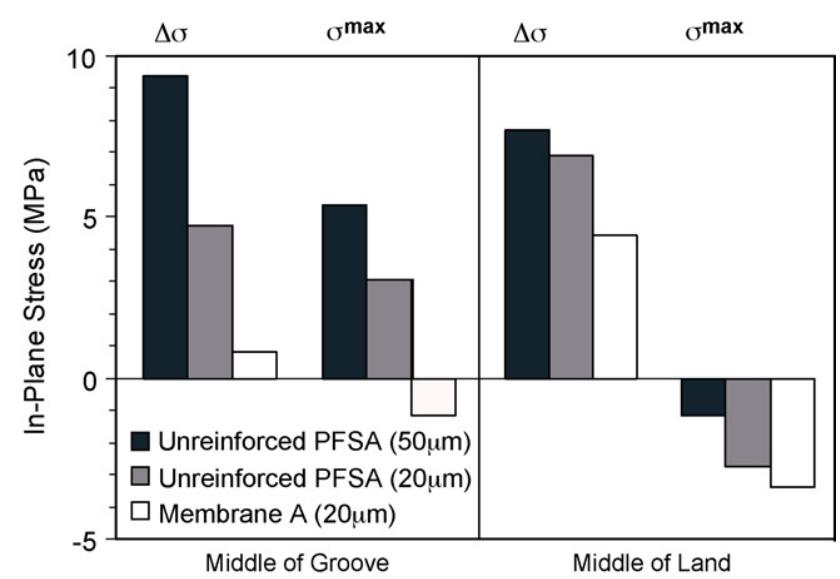

Fig. 15. The in-plane stress amplitude $\Delta \sigma$ and the maximum in-plane stress $\sigma^{\text {max }}$ at the two ends of the PEM for the Membrane A and unreinforced PFSA membrane of thickness 20 and $50 \mu \mathrm{m}$.

yield strength. Consequently, the hydration-dehydration cycles lead to cyclic yielding, i.e., an increase (forward yielding) and decrease (reverse yielding) in the magnitude of plastic strains, in the unreinforced PFSA membrane, while the plastic strain remains zero in Membrane A Fig. 14.

The in-plane stress amplitude and the maximum in-plane stresses during the fourth cycle at the middle of the groove and the middle of the land of the membranes are summarized in Fig. 15. The in-plane stress amplitude for Membrane A is lower than that for the unreinforced PFSA membrane at both locations. Moreover, the maximum stress for Membrane A is compressive and smaller in magnitude compared to that of the unreinforced PFSA membranes, which is tensile at the left end. These results are due primarily to (i) the lower in-plane swelling and (ii) higher yield strength of Membrane A.

The properties used for the unreinforced PFSA membranes are based on testing of a membrane with thickness $50 \mu \mathrm{m}$. However, we have so far assumed a thickness of $20 \mu \mathrm{m}$ for a direct comparison with Membrane A. We will now investigate the stresses in an unreinforced PFSA membrane of thickness $50 \mu \mathrm{m}$ to explore the effect of membrane thickness on the mechanical response under the same load conditions. Resulting stress amplitudes and maximum stresses are summarized in Fig. 15. The graph shows that increasing the thickness of the unreinforced PFSA membrane, increases both the in-plane stress amplitudes and the maximum in-plane stresses. This suggests that a thinner membrane results in lower mechanical stresses. It might seem counterintuitive that a thinner membrane results in lower stresses. However, this problem is strain controlled, thus increasing the thickness results in increasing stiffness which may, as it appears to do in this case, increase the stress level. This stress increase for the thicker membrane was also seen in our previous studies [11].

The numerical results presented here coincide with experimental studies of durability of fuel cells conducted by other researchers, e.g., Kolde et al. [11], which suggest that development of membranes with lower in-plane swelling strains and 
higher yield strength would be a significant contribution towards more durable fuel cells.

\section{Concluding remarks}

The hygro-thermo-mechanical properties and response of a class of reinforced hydrated perfluorosulfonic acid membranes (PFSA), referred here to as Membrane A, have been investigated through both experimental and numerical modeling means. Experimentally, a set of critical material properties; Young's modulus, proportional limit stress, break stress and break strain, along with the swelling strains were determined. Numerically, these constitutive parameters were implemented in a mechanicsbased set of simulations (using finite element analysis) to establish the mechanical response during simulated fuel cell operation.

The material properties were measured in a custom-built temperature and humidity controlled chamber at 16 temperature and humidity combinations, ranging from 25 to $85^{\circ} \mathrm{C}$ and 30 to $90 \%$ relative humidity. These tests show that the membrane material under investigation exhibits much higher Young's modulus than unreinforced membranes. For example, Membrane A has a Young's modulus exceeding $500 \mathrm{MPa}$ in both directions at $25 \mathrm{C}$ and $30 \% \mathrm{RH}$, whereas the unreinforced membrane is only around $200 \mathrm{MPa}$ [1]. Membrane A also has higher proportional limit stress and higher break stress at all temperature/relative humidity points considered, compared to the unreinforced membrane tested previously. Moreover, the in-plane dimensional changes due to swelling of Membrane A are smaller than those of the unreinforced PFSA. The maximum dimensional change for Membrane A at $85^{\circ} \mathrm{C}$ and $90 \% \mathrm{RH}$ in the machine direction is less than $2.5 \%$ whereas that for the unreinforced membrane is about $12 \%$.

In order to establish the potential effect that the properties of Membrane A can have on the mechanical durability of a fuel cell, mechanics-based numerical simulations utilizing the finite element method were conducted. A unit cell approach was undertaken, where a particular fuel cell testing sequence simulating accelerated humidity testing, was modeled. The load imposed keeps the membrane at elevated temperature $\left(85^{\circ} \mathrm{C}\right)$ and linearly cycles the relative humidity between the initial $(30 \% \mathrm{RH})$ and the hydrated state $(95 \% \mathrm{RH})$ at the cathode side of PEM. The numerical simulations show the inplane stresses for Membrane A remain compressive during the cycling. Compressive stresses are advantageous with respect to fatigue loading, since compressive in-plane stresses will significantly reduce the slow crack growth associated with fatigue failures.

In summary, the reinforced PFSA membrane exhibits higher strength and lower in-plane swelling than the unreinforced membrane used as a reference. This results in lower stresses and less plastic deformation during the simulated fuel cell operation, which should result in higher fuel cell durability.

\section{Acknowledgements}

This research has been supported by grants from W.L. Gore \& Associates Inc. and the State of Delaware Development Office.

\section{References}

[1] Y. Tang, A.M. Karlsson, M.H. Santare, M. Gilbert, S. Cleghorn, W.B. Johnson, Mater. Sci. Eng. A 425 (2006) 297-304.

[2] J.T. Uan-Zo-li, The effects of structure, humidity and aging on the mechanical properties of polymeric ionomers for fuel cell applications, Master thesis, Virginia Tech, 2001.

[3] D. Liu, S. Case, J. Power Sources 162 (2006) 521-531.

[4] M. Crum, W. Liu, Proceedings of the 210 ECS Meeting, Cancun, Mexico, 2006.

[5] Y.-H. Lai, C.S. Gittleman, C.K. Mittelsteadt, D.A. Dillard, Proceedings of the 3rd International Conference on Fuel Cell Science, Engineering, and Technology, Ypsilanti, MI, United States, 2005, pp. 161-167.

[6] X. Huang, R. Solasi, Y. Zou, M. Feshler, K. Reifsnider, D. Condit, S. Burlatsky, T. Madden, J. Polym. Sci.: Part B: Polym. Phys. 44 (2006) 2346-2357.

[7] A. Kusoglu, A.M. Karlsson, M.H. Santare, S. Cleghorn, W.B. Johnson, J. Power Sources 161 (2006) 987-996.

[8] Y. Tang, M.H. Santare, A.M. Karlsson, S. Cleghorn, W.B. Johnson, J. Fuel Cell Sci. Technol. 3 (2006) 119-124.

[9] A. Kusoglu, A.M. Karlsson, M.H. Santare, S. Cleghorn, W.B. Johnson, J. Power Sources 170 (2007) 345-358.

[10] R. Solasi, Y. Zou, X. Huang, K. Reifsnider, D. Condit, J. Power Sources 167 (2007).

[11] J.A. Kolde, B. Bahar, M.S. Wilson, Electrochem. Soc. Proc. 95-23 (1995) 193-201.

[12] R.M. Penner, C.R. Martin, J. Electrochem. Soc. 132 (1985) 514-515

[13] J.A. Kolde, B. Bahar, M.S. Wilson, T.A. Zawodzinski, S. Gottesfeld, Proceedings of the 1st International Symposium on Proton Conducting Membrane Fuel Cells, vol. 95-23, The Electrochemical Society Inc., Pennington, NJ, 1995, pp. 193-201.

[14] B. Bahar, A.R. Hobson, J.A. Kolde, Internal Composite Membrane, United States, patent no. 56154, 1995.

[15] B. Bahar, A.R. Hobson, J.A. Kolde, Ultra-thin Integral Composite Membrane, United States, patent no. 404853, 1996.

[16] S. Cleghorn, J. Kolde, W. Liu, in: V. Wolf, L. Arnold, G. Hubert (Eds.), Handbook of Fuel Cells-Fundamentals, Technology and Applications, John Wiley \& Sons Ltd., 2003.

[17] W. Liu, K. Ruth, G. Rusch, J. New Mater. Electrochem. Syst. 4 (2001) 227-232.

[18] A. Collier, H. Wang, X.Z. Yuan, J. Zhang, D.P. Wilkinson, Int. J. Hydrogen Energy 31 (2006) 1838-1854.

[19] P. Costamagna, S. Srinivasan, J. Power Sources 102 (2001) 242-252.

[20] A.B. LaConti, M. Hamdan, R.C. McDonald, in: W. Vielstich, A. Lamm, H. Gasteiger (Eds.), Handbook of Fuel Cells: Fundamentals, Technology and Applications, vol. 3, Weiley, Chichester, England, 2003, pp. 647-662.

[21] M. Crum, W. Liu, Effective Testing Matrix for Studying Membrane Durability in PEM Fuel Cells. Part 2. Mechanical Durability and Combined Mechanical and Chemical Durability, vol. 3, Electrochemical Society Inc., Pennington, NJ, United States, Cancun, Mexico, 2006, pp. 541-550.

[22] ABAQUS, ABAQUS Analysis User's Manual, HKS Inc., 2003.

[23] S. Suresh, Fatigue of Materials, Cambridge University Press, New York, 1991.

[24] R. Hill, The Mathematical Theory of Plasticity, Oxford University, Oxford, 1950. 